\title{
Slow Television
}

\section{A Successful Innovation in Public Service Broadcasting}

\author{
Roel Puijk
}

\begin{abstract}
Public-service broadcasters are compelled to seek innovative ways to fulfil their publicservice functions in an increasingly competitive environment. The Norwegian Broadcasting Corporation (NRK) has been experimenting with new programme formats and cross-media concepts. The concept of slow television was developed by the regional office in Bergen. On July 16, 2011, they started a five-day live broadcast from one of the cruise ships that sailed up the Norwegian coast from Bergen in southern Norway to Kirkenes near the Russian border. The broadcast was a huge success. I take this programme as a case study and provide an analysis from the perspective of innovation within public-service broadcasting. The article addresses the following questions: 1) In what way was the programme innovative? 2) How was the programme accepted and produced? 3) What accounts for the success of the broadcast in terms of number of viewers and popular engagement?
\end{abstract}

Keywords: slow television, public service broadcasting, innovation, production, interactivity, Norway

\section{Introduction}

Television is changing - digitization, new platforms and increased competition are undermining traditional ways of producing television. In the post-television era new ways of reaching and engaging viewers are being sought in order to stand out in the ever-intensifying battle to win viewers' attention. One of the strategies that commercial channels have used in particular is the introduction of different reality concepts in which ordinary people participate in situations that are often unreal. Some of these concepts, such as Big Brother or Pop Idol, gradually escalate and culminate in an event-like finale. Unlike classic media events (Dayan \& Katz 1992), these are organized by television. Kjus (2008) coined the term 'event-media' for these concepts, where different platforms - television, the Internet, mobile phones - collaborate and viewers are involved in participatory activities (e.g., voting).

Much of the ongoing academic discussion on public-service broadcasting has to do with convergence and the change from public-service broadcasting to public-service media (cf. Lowe \& Hujanen 2003, Lowe \& Bardoel 2007, Lowe 2010). Content innovation has been largely overlooked. Public-service broadcasters must also seek innovative ways to fulfil their public-service functions in an increasingly competitive environment (Wurff \& Leenders 2008). They too may engage in event media, but they are more re- 
stricted than commercial actors are, because they are supposed to pursue democratic, ethical and national values rather than market success.

In-house production companies like the $\mathrm{BBC}$ or the Norwegian Broadcasting Corporation (NRK) are in a special situation. Introducing innovation may be difficult in an organization in which continuous production is paramount (Christensen 2008). Creative production, such as film, is often organized by means of flexible specialization (Lorenzen 2009). Whereas commercial channels obtain flexibility by outsourcing production, inhouse production companies tend to develop bureaucracies that are more focused on the production of a continuous stream of programmes. Although new internal organizational forms have been introduced (e.g., the separation of scheduling and production, internal markets, partial outsourcing, etc.), the existence of departmental boundaries and the regular production of established television series tend to consolidate organizational forms and routines (Born 2005, Puijk 2013). Moreover, the use of new platforms challenges established routines in traditional media, but when well-coordinated they can also reinforce each other (Kjus 2008).

The present article is based on a case study of a national television event in Norway that followed a different pattern. Hurtigruten was a non-stop direct television broadcast lasting nearly 135 hours and filmed from the Norwegian Coastal Express. It was a bottom-up initiative from one of the regional offices that had organized and coordinated this innovative television programme with a minimum of costs. Besides fulfilling the main objectives of the NRK's public-service remit, it was highly successful in terms of viewing figures and popular Internet activity.

The programme was unusual and could easily have failed: the proposal of such a bizarre programme might have been rejected by the broadcaster; there might have been technical and/or organizational problems; or the audience might not have wanted to watch it. What were the conditions that made this innovation a successful programme? To answer this question, I will look at the different phases of production. I start by identifying the origin of the programme and the process that led to its acceptance. One of the achievements of the producers at the regional office was that they were able to convince the organization to devote one channel for five and a half consecutive days, 24 hours a day, to the broadcast. The next question is: How did they organize the project involving different departments to make a successful broadcast? The third question deals with why the programme was a success.

\section{Hurtigruten Minute-by-Minute - a Multiplatform Concept}

The NRK's regional office in Bergen developed the concept of 'minute-by-minute' or slow television. On July 16, 2011, they started a five-day live broadcast from one of the cruise ships that sails up the Norwegian coast from Bergen in the southern part of the country to Kirkenes near the Russian border in the north. The broadcast boosted the market share of the channel from an average of 5.3 (2011) to 36.0 per cent during the broadcast. The broadcast was also streamed live on the Internet, enabling people around the world to watch.

Although the viewers were clearly enjoying the programme, little happened at first. It recorded in real time the ship's course from the time of its departure from Bergen until its arrival in Kirkenes. The broadcast consisted mainly of static pictures taken from the 
Norwegian coast, fjords, sunsets and pictures taken from the berths while the boat was in harbour, sometimes interspersed with brief interviews with passengers and crew.

As the broadcast progressed, the activity of the local population became more pronounced - Hurtigruten was followed by a stream of small motor boats and people on the shore held up signs with greetings or messages to viewers, etc. While Hurtigruten was in harbour, locals came to watch while local bands, dancing groups and individuals staged various performances. For many viewers, the climax was when Hurtigruten crossed the Royal Yacht on its way south in Northern Norway. The Queen, who was prominently visible on deck, waved and took pictures of Hurtigruten.

The programme also implemented recent developments related to the extensive use of new media: It was streamed live on the Internet, enjoyed considerable activity on accompanying social media (Facebook, Twitter) and a chat. After completion of the broadcast, it could be downloaded in HD with BitTorrent technology, and data from several sources (e.g., geo-positioning data, ratings) were published so that viewers could use them in their mash-up activities.

\section{Innovation in Public Service Television}

According to Schumpeter, the founder of innovation studies, innovation deals with entrepreneurial activity defined as "the doing of new things or the doing of things that are already being done in a new way" (Schumpeter 1947/1983: 223). The economic rationale so often seen as spurring innovation in commercial broadcasters does not apply to their licence-based, public-service counterparts, such as the NRK and BBC. The link between success in the market and income is weak, at least in the short term. Public-service broadcasters are, however, dependent on politicians for their income and they require general legitimacy. As Nissen (2006) argues, legitimacy is dependent on a programming profile that both differentiates itself from their commercial competitors and has a reasonable reach amongst viewers. Licence-based broadcasters are independent of ratings for their income, and therefore they take fewer risks when experimenting with new programmes. And of course they have the advantage of avoiding what irritates viewers most when watching television: commercials (Smith, Meurs \& Neijens 2006).

Mandates like the BBC's Charter (2006) or the NRK's bylaws [NRK-plakaten 2012] restrict the kinds of programmes they are permitted to produce, but both documents include statements on creativity and innovation. The public purpose of the BBC includes "stimulating creativity and cultural excellence" (Charter $\S 4$ ), and "The NRK shall be innovative and contribute to development of quality" (Article 15).

Innovation can take place at different levels, such as the level of products, processes, organizations or markets, but these may also be interrelated. Innovation implies doing new things and breaking with routines. This poses a series of challenges during the different phases of production. While it may be feasible to come up with new ideas, it may also be difficult to get them accepted and carried out because change is often met with resistance. New practices often require new organizational forms (Christensen 2008).

The NRK has been experimenting with new programme formats, especially with humour programmes during the 1990s (Ytreberg 1999, Kjus 2004). They have also developed different cross-media concepts (cf. Enli 2007, Kjus 2007, Sundet 2008, Puijk 2011). In line with organizational theory, the NRK often organizes innovation as multi- 
disciplinary projects that accommodate experimentation. Sundet, for example, analyses the production of a video series for mobile media and shows "how the NRK managed to establish an experimental space within the institution where international trends and new services could be tested" (Sundet 2008: 282).

While innovations are often organized as projects, they can involve different existing departments at the production stage. In large organizations, coordination and cooperation are often easier within departments and units than between them (Pfeffer 1981). As soon as more units are involved, coordination and non-routine ways of working become challenging. Smooth working relationships can be vitiated by differences in values, priorities and budgets - tendencies that have also been recognized within media companies (McQuail 2005).

In cross-media projects, the different platforms have different functions in supporting each other (Philipsen 2007). How the platforms are organized and the content coordinated is essential to eliciting a response from the audience. But coordination of different platforms is also challenging. In his analysis of the production of one of the NRK's first major cross-media programmes, Greatest Norwegian, Kjus (2007) points out that professionals from different media had different ways of thinking and working that clashed. Others too have highlighted different ways of thinking and routines between established broadcasting media and online media (Erdal 2007).

Because Hurtigruten was such a successful innovative production, the main question to be answered concerns how they coped with these challenges during the different phases of idea creation, planning, organization and realization in order to identify the factors that contributed to the success of this production.

\section{Methods}

The present article is based on a case study. Case studies are valuable when studying phenomena in depth. To study programme innovation, case studies are particularly appropriate for determining how the organization tackles an innovative programme that diverges from the established routines of production. As mentioned, Hurtigruten was not only a creative concept developed within one of the NRK's regional offices, but also an innovative production involving several departments and platforms. By using a non-routine case, we can shed light on how internal processes work in the face of the challenges of innovation as well as how different elements are composed for the receiving audience.

The main method used was qualitative interviews with a purposive sample of informants. I interviewed the main actors involved in the project: the Project Leader and the Head of Programming at the Bergen office. The Head of Programming described his role as that of executive producer, but they often worked as a team, such as when they visited various departments to invite people to participate in the project and during the broadcast itself. Furthermore, I interviewed the Commissioning Editor responsible for factual programming and children's programmes and a representative of the broadcaster's new media section at the NRK's headquarters in Oslo. I also gathered additional information in the form of ratings, the television programme itself and the chat that accompanied the live streaming (including Twitter messages). Of course without direct research on the viewers, my analysis of the question of why people watched is somewhat more subjective. 


\section{Creativity and Innovation: What's New?}

Several external actors acknowledged Hurtigruten to be an innovative programme. Guinness World Records recognized it as the "Longest live TV documentary broadcast". The producers received the Gullruten Award for the most innovative television programme in Norway. In addition, the Norwegian part of UNESCO's Memory of the World programme has included the programme (Kulturrådet 2012).

These features indicate that Hurtigruten was a successful innovative programme, but what exactly was new or innovative? Even though it was a complex and challenging production, existing production technologies were used. Moreover, the Internet solutions were based on existing technologies that were used as adaptive innovations. More original - at least on television - was the 'minute-by-minute' concept, though here too forerunners can be found.

When asked for the background story of Hurtigruten the interviewees referred to a television programme about the train journey between Bergen and Oslo (Bergensbanen), which was also produced in Bergen and broadcast in November 2009. The programme was part of the celebration of the Bergen-Oslo railway centenary. This seven-hour programme documented the whole trajectory, and despite the fact that it had been prerecorded, the broadcast followed the train schedule. Each time the train went through tunnels archival material from the railroad history was shown. The NRK's channel two, NRK 2, broadcast the programme and it proved to be a success with ratings beyond all expectations: some 1.2 million (out of the Norwegian population of five million) watched part of the programme. The NRK did not provide any special Internet follow-up, but the programme elicited a great deal of comment on Twitter and Facebook.

The success of this programme inspired the producers to make an even more ambitious programme. Their preparations of the Hurtigruten reflected several experiences from the Bergensbanen project. While editing Bergensbanen, they realized that the next programme would have be live and interactive: they would need to be able to communicate with people during the trip, to engage them and facilitate their participation while the broadcast was on the air.

The live coverage would present technical challenges, but they decided that it would as far as possible be live, without pre-edited material and pre-arranged content: only pictures of landscape, harbours, together with a few interviews with passengers, crew and bystanders in the harbours. As the Project Leader explained:

This [indicating a picture of mountains, sea and sunset] is a beautiful picture that can be shown for a long time. But we decided that this [pointing to a picture of the gangway of Hurtigruten] is a beautiful picture too.[ ...] When we are docked in the harbours of Bodø or Tromsø for four hours, this picture should be shown for as long as it takes to arouse your curiosity and you start to distinguish the details. We should resist the temptation to produce a regular broadcast in all the harbours, which normally we would have done by filling the programme with hours' worth of television content. (Project Leader, 22.05.12)

As regards the product, the main creative achievement was that the programme negated the main tendencies in television programmes: the programme consisted mainly of overview pictures of the landscape accompanied by ambient sound, the editing pace was extremely slow, there was no narrator and virtually no dramatic development. What was 
shown was shown in real time, without ellipses and without adding additional material in the form of performances. Although real-time broadcasts are used in live coverage of televised events (e.g., live coverage of the Tour de France), owing to the long periods involved and the lack of external or prearranged attractions, the Hurtigruten broadcast was more akin to observational forms like CCTV or the live web feed of Big Brother.

As for technological innovation, the production involved a range of cutting-edge technologies, not previously used by the NRK. The live streaming with 'rewind' facility presented a new challenge and this was the first time that the NRK had ever used the combination of broadcasting with geo-positioning. The chat, Facebook pages and Twitter account are existing applications.

\section{How to Realize a Crazy Idea?}

In order for large organizations to carry out creative projects, they have to develop not only new ideas, but also new organizational spaces. Organizational routines are often geared towards continuous production, but not innovation. In this case, it was a bottom-up process where individuals at the lower levels initiated innovation. We can conceptualize this as an 'intrepreneurial' activity (Bessant \& Tidd 2011:272). Intrepreneurs use existing organizational and bureaucratic structures to realize new products (programmes). The main question is how the existing structures interact with the intrepreneurs and their ideas.

The production process can be split into different phases. Because the NRK is an integrated production company, all phases and actors are internal, but the different parts and actors are involved in the different phases. We can distinguish two main phases:

1) Acceptance: The conceptual phase where the idea is created and pitched at the actors controlling the economic and technical resources necessary for realizing ideas - in this case the creation of the concept and the dialogue with the Broadcasting Department (also called Broadcaster).

2) Production: the actual realization of the allocated resources, where the plans are transformed into programmes. Here different competencies and material resources are mobilized and coordinated.

\section{Acceptance}

The Hurtigruten programme was a follow-up of the successful Bergensbanen, which involved the same people at the regional office. The fact that a milieu outside the NRK's television centre in Oslo pitched this programme is perhaps no coincidence. As the Project Leader explained:

We probably felt we were in an underdog position [...] many of the fixed schedules are produced in Marienlyst [the NRK's headquarter in Oslo], where the Culture Department has its budgets, the Factual Department its budget [...] and they could plan within this budget [...]. For many years we have been living off selling ideas for single programmes. [...] Our culture is characterized by the ongoing development of new ideas. (Project Leader, 22.05.12) 
The Head of Programming first contacted the Broadcasting Department by telephone to air the idea and a written application was then made, but the real decision was based on a series of meetings between the regional unit and the Broadcasting Department. The Commissioning Editor compared their broadcasting model with that of the BBC:

$[\ldots]$ you cannot just base these decisions on a piece of paper alone. Thus there were meetings and discussions and that is the way we work all the time. [...] We work with something we call the 'dialogue model', and that is a bit different [from the BBC model]; it is not as if the commissioning editors have all the power and decide that this one and this, but not this, are accepted. That is not the way we work. [....] It is clear that the 'dialogue model' we have implies that we decide on our commitments together [with the production departments] and that we find good solutions through discussion. It may be time-consuming but it is more robust and works better for everyone. (Commissioning Editor, 22.06.12)

The NRK's Broadcasting Department only consists of a few people and the commissioning editors rely on extensive dialogue with the production units within the organization. Likewise, Hurtigruten was developed as a dialogue between the Commissioning Editor and Head of Programming/Project Manager.

The Commissioning Editor argued that it was important not to dismiss such an unusual idea but to weigh it up with a positive attitude. She argued that they thought it was important to consider what would happen were they to turn it down. According to the Head of Programming, they first discussed whether the NRK should produce this programme. After some discussion they reached a consensus: the NRK not only should make the programme, but they had an obligation to make it.

This is a project the NRK not only can do, but must do, because we are the only ones who can do it. (Head of Programming, 15.06.12)

Apart from the positive reaction to the project, a combination of factors contributed to its acceptance. The Commissioning Editor stated that the remit of the NRK was the main reference point, but that other factors were also involved:

We judge the programme from the point of view of scheduling in relation to the channel. Can we occupy this channel for five and a half days? Is that possible and how does it fit in with the other programmes we broadcast? Is it financially viable? That is always a question. And we judge it in relation to the audience and whether it will be received well. And it is undoubtedly within our remit because no one else would think of doing this. A commercial channel cannot do this. (Commissioning Editor, 22.06.12)

Because there were no expenses for performances the costs were extremely low. As the Project Leader mentioned: "For the price of two hours of documentary they got 135 hours". This amount - roughly $250,000 €$ - was paid in part by the co-producers from the neighbouring Nordic countries.

Because of the lighting conditions, the broadcast had to take place during June when the midnight sun shines all night. During this off-season period the broadcaster did not need to take the established schedule into account: 
This was low season on NRK 2, the second half of June. So the regular slots had their summer break. It would have been different had it been in February, for example. Then it would have been considered in relation to the regular programmes. There would be many programmes that we would not have taken away. We also consider what we take away from the audience, because it is not as though everyone necessarily wanted to watch Hurtigruten either. (Commissioning Editor, 22.06.12)

The Head of Programming mentioned that there was little risk during the summer season, given that the ratings are in any case low. In addition, the Broadcasting Department had requested theme evenings and innovation.

When we pitched our concept to the Broadcaster it was accepted not only because a wish for theme evenings on NRK 2 had been expressed, but also because the Broadcaster wanted innovation. The Broadcasting Department had made it clear: innovation, both entirely new things but also innovation within established schedules. (Head of Programming, 15.06.12)

To sum up: even though the proposal for a continuous broadcast of 135 hours seemed outrageous at first, it turned out to fit rather well into the broadcaster's planning process. The programme accorded with the NRK's guiding principles, in particular Article 14 ("The NRK shall strengthen Norwegian language, identity and culture") and Article 15 ("The NRK shall aspire to achieve high quality, diversity and innovation"). The costs were low, as was the risk of not reaching as many viewers as they would have done with alternative programming. After winning the broadcaster's support and securing the necessary funding, the next phase was the initiation of the production process, which involved various people and departments.

\section{Production}

Many departments were involved in the Hurtigruten project. NRK's new media section was involved from the start. They had been involved in the Bergen Banen project after its completion and they went on to plan the cross-media part of Hurtigruten - the web-page including net-stream, chat and metadata connecting the various elements live. The Head of Programming and the Project Leader spent considerable time travelling to inform different departments in Oslo and regional offices throughout the country. Because they coordinated the Norge Rundt programme (a national programme containing reports from all of NRKs regional offices), they already had existing connections that could be used.

Participants for the project were then recruited. The recruitment was ad hoc, and only the most enthusiastic were selected. The Head of Programming and the Project Leader felt their role as outsiders allowed them to be flexible and effective when organizing the project:

Most joint projects that are decided from the top use lots of energy on cooperation itself, but here in our project it just happened because we chose and asked people whom we knew had expert knowledge and who liked the project. Our rule was to pick only those people who smiled when they heard about the project. (Head of Programming, 15.06.12) 
The Project Leader agreed but also suggested that top management's stress on an ethos of more cooperation in recent years may have facilitated this:

I think that this coincided very much with a general change in the NRK, with the appointment of Hans Tore Bjerkås [General Director, 2007-2013], his slogan: "One NRK", the urge to cooperate. These were things that we had been told a couple of years earlier - that we have to cooperate and stand out as one NRK to our public. We went through a period with a lot of internal competition and many internal divisions, which was perhaps necessary to control the budgets and to get a grip on certain things, but what Hans Tore Bjerkås did, as I experience it, was to make us relax more so now we should cooperate [...] In terms of cooperation I think that Hurtigruten would have been harder to accomplish four or five years ago. (Project Leader, 22.05.12)

The project received support from all parts of the NRK. The broadcast was backed up with announcements and promos on all NRK platforms.

During the broadcast a group of 23 people was aboard the ship, including the Head of Programming, the Project Leader and the Engineer from the new media section. The latter explained that they worked in a more flexible way than usual:

During the Hurtigruten project everyone aboard was multi-functional. There was no-one who did only one thing - everyone was able to perform most functions. The whole project was characterized by the fact that people throughout the NRK system were recruited and these were people who wanted to be included and who were very multi-functional and could accomplish many tasks. So the job was carried out by a small on-board team. (Engineer, 30.5.12)

The broadcast was live, and because the premise was "reality should reveal itself", little content was prepared in advance. When plans for the broadcast were made public, they received many requests offering local performances along the route. The Project Leader made it clear that they were interested in knowing what people were planning locally but refused to commit. The whole broadcast was largely improvised, as they had no commitments and only showed the voyage and what might have been arranged locally. In this way, they avoided the content-production aspect of the broadcast, with all the resources (both human and financial) normally spent on this.

\section{What Makes a Success?}

The producers were surprised by the amount of interest generated by the programme.

Well, I expected we would have at least as many viewers as we would normally have on NRK 2. That was our point of departure: if we can make that, it is good enough. In some ways that is a success. I had even imagined that there might be a few more - because this is so special that it draws a bigger audience because of its originality. (Head of Programming, 15.06.12)

Despite low expectations, the programme was undoubtedly a huge success for NRK 2. At their highest the ratings exceeded 800,000 viewers on the first two days and around one million the last three. Only the most popular weekend programmes on the main channel 
NRK 1 reach these figures. Similarly, Internet activity greatly exceeded expectations. The chat spawned a great deal of activity, with some 40,000 responses posted over the five-day period (including Twitter messages). The programme's Facebook page was also exceptionally active.

Some of the best-known fjords and mountain landscapes in the country were featured in the broadcast. This in itself ensures spectacular television images, especially in HD quality. One of the 11 cameras was a stabilized super-zoom camera (Cineflex) that produced impressive pictures. It included the longest day of the year, and the days became longer as the boat travelled northwards; during the last three days, the sun did not set, permitting some magnificent shots of the sun just above the horizon. The programme's popularity can also be interpreted as a reaction to increasingly faster television and can be related to the slow-food/slow-city movements.

Factors specific to Norway also played a part. The programme may also be said to resonate with the value of nature in the indigenous culture (Eriksen 1996) and Norwegians' interest in ordinary people. Nature programmes and programmes on the whereabouts of ordinary people from different parts of the country draw relatively large audiences. In addition, Hurtigruten is a powerful symbol. The ships are combined cruise ships and ferries that have been travelling along the coast of Norway since 1893 and are well established in the Norwegian consciousness. These ships are a familiar part of the long Norwegian coast, sailing at regular hours on a daily basis, and they have traditionally been an important means of communication.

The viewing figures indicate that at the outset many people watched long stretches of the programme. Some reported that watching had a hypnotic effect on them. During the third day of the broadcast (a Sunday) many people watched during daytime. People also frequently reported that they stayed awake in the middle of the night to see their place of birth or other places that occupied a special place in their memory.

The programme received much support in the NRK: it was promoted heavily on the NRK's channels. NRK1 and the NRK's Internet site referred to it both before and during the broadcast. This cross-promotion, where different outlets are used to mutual benefit, is a traditional form of cooperation within media businesses (Dailey 2005).

Although it is hard to document without further evidence, I suggest that the success of the broadcast can be largely attributed to the possibility of interactivity. Three forms of interactivity can be distinguished.

\section{1) Participation on television}

As the live broadcast lasted several days and Hurtigruten followed an established timetable, people living along the coast knew when their places would be shown. On the first day there was little activity, but successively more and more activity could be noticed, with people on shore waving or dressing up and small boats accompanying Hurtigruten along with people holding up placards. Activity increased during landings, particularly north of Trondheim (after the second day). Hundreds of people came to celebrate and brass bands and other small orchestras played, along with other performances. In short, a host of popular cultural activities accompanied the arrival of Hurtigruten. The cameras of course captured and transmitted this rather carnivalesque atmosphere. This 'selfgenerated' content was one of the success factors: It attracted viewers and contributed to a form of interactivity during the broadcast. 
Although the producers had not prepared any entertainment as part of the broadcast, the public along the route provided spontaneous entertaining content that complemented the picturesque shots of nature. It is safe to suggest that this in turn attracted more viewers in a positive feedback loop, for one never knew when a funny, touching or entertaining element would occur, but something interesting was bound to happen at some stage. Of course the dramaturgy of the broadcast did not follow an Aristotelian or Hollywood model, with exposition, climax and dénouement, but the series of smallscale performances represented minor attractions along the way thereby contributing to the programme's popularity.

\section{2) Participation on the Internet}

Another way of participating was through the Internet, in particular through the chat that ran parallel to the live streaming on nrk.no/hurtugruten. With 40,000 postings during the five days, this chat was active throughout, but it rose from 3,400 posts on Friday the 17 th to 11,000 on Tuesday the 21 st. In general, the activity on the chat correlated with the television ratings $(\rho=0.71)$. The chat included several themes, but especially interesting in our context is the amount the production team contributed to the chat. They were very active in responding to questions, providing information about different aspects of the production, the voyage and the places on the way. The chat proves that they responded to viewers' remarks about the broadcast, for example, by adjusting the music they were playing. Thus, the interaction between the chatters and the production team influenced the television programme itself. This kind of audience participation is not uncommon in contemporary television production: the voting element in many musical competitions and other reality programmes, the on-screen chat in SMS-Television and the posing of questions through phone-in allow audiences to influence television programmes (Enli 2007). Hurtigruten provides another instance of this interactivity.

\section{3) Participatory context}

A third way was the participatory context provided by the nrk-beta blog (nrkbeta.no). This is an ongoing popular blog managed by relatively young NRK employers engaged in developing technology and new media. This blog is followed by Norwegians interested in technology. It covers a range of topics including new gadgets, background information on programme production, discussions about Internet content distribution and piracy. The blog relates to the media largely in terms of a digital-culture attitude, such as holding open dialogues between producers and consumers, using crowd-sourcing, sharing programmes through bit-torrent files, and using Creative Commons licences. This reflects Jenkins' description of 'convergence culture' (Jenkins 2007). The bloggers work in the new-media department of the Broadcasting Department and they were involved in the Hurtigruten project in different ways. Before the broadcast, the bloggers shared some of the production challenges and asked their readers for feedback and ideas. They were responsible for the new-media aspect of the project (streaming, meta-data, interactive map, chat, etc.). Once the broadcast had finished, they distributed different data about the broadcast (ratings, clicks, GPS positions) and made the whole programme available for downloading. They also initiated a competition for the most creative use 
of the data by viewers. This resulted in some mash-ups, with new combinations of maps and ratings, time-lapses and more.

There is of course a marked difference in the numbers of people involved in the three interactive forms: thousands gathered on the landing places, the harbours and the coastal area to admire the ship. They vastly outnumbered active chatters. Many lurkers dropped in and looked at the Facebook pages. According to the NRK's Facebook operators, there were 12 million visitors on the Facebook page and some 57,000 shares. This indicates that television and the second screen - in part simultaneously - comprised the same experience, with different platforms supporting each other. The more active interactivity in the form of mash-ups was of course much more limited, but it may have engaged some of the younger people who do not make up the NRK's main market but who nevertheless function as opinion leaders amongst their peers.

\section{Conclusions}

Given the competition with commercial channels, public-service broadcasters have to update their content to fulfil their public-service obligations. Large in-house production companies have to handle innovation in different ways from companies, all of whose production is outsourced. They may establish separate projects outside the established structure, create space for innovation within existing departments or outsource parts of their production. Hurtigruten followed none of these models - it was initiated bottom-up in a peripheral part of the organization, accepted by the controller, even though it made an exceptional claim on broadcasting time, and involved cooperation between different media and departments. The case study approach used here serves to highlight both the different success factors involved in the different production phases, while at the same time indicating the interconnections.

The NRK appears to be receptive to innovation. Hurtigruten was a unique media event where many new ideas came together as a unique product - unique enough to be sold as a television format abroad (see: http://www.nrk.no/kultur/1.11341016). In many ways, this programme ran counter to the main tendencies in competitive television today: the tight scheduling of programmes (even on public-service channels), the tendency towards constant drama and/or entertaining content, fast editing and serialization. We can sum up the main success factors of Hurtigruten at the level of the project, of the NRK and in relation to its content and appeal for its audience (cf. Habann 2006).

At the project level, it is an example of 'intrapreneurial' activity (Bessant \& Tidd, 2011: 272). The somewhat peripheral position of the project initiators in the organizational structure seems to be advantageous - they were forced to be creative and fight for their proposal. Having a track record for good ideas of course helped to convince the broadcaster of the validity of their project.

Another success factor at the project level is the producers' active networking with different departments, arousing enthusiasm for the project and recruiting appropriate competencies into an interdisciplinary team. The team's enthusiasm and flexibility in performing different tasks were also crucially important factors.

As far as the NRK was concerned, flexibility and cross-promotion were key success factors. The Broadcasting Department as a central decision-maker in the scheduling process proved to be open to unorthodox ideas. The fact that the initial question was 
transformed from "can we do this?" to "can we afford not to do this?" shows a nonbureaucratic attitude and flexibility in application of the 'dialogue model', which is favourable to innovation. At the same time, we also saw that other factors (alternatives, timing and cost) contributed to the positive decision.

Further, the backing that the project received inside the NRK, which resulted in comprehensive promotion on the NRK's other channels and technological support for other platforms, was a sign of the NRK's support of innovative programmes. Internal emphasis on cooperation also contributed to the organization of this demanding production.

The straightforward 'minute-to-minute' ethos (recording events as they evolved rather than arranging them) had implications on several levels. It meant that planning could be focussed on finding technological solutions to get a stable signal from a moving vehicle, while no energy and resources were expended on arranging performances. This resulted in vastly reduced financial outlay, more manageable production conditions, and ultimately more space for ordinary people to play a part.

Interactivity and cultural resonance played an important role in attracting viewers. The cultural value of the coast, Hurtigruten, nature and folk life accounts for the success of many nature and folksy programmes in Norway. Normally serialization enables television to establish long-term commitments in their audience. In this case, the commitment was limited to one period, but the period in question was long enough to arrange an event that dominated the public consciousness and allured many Norwegians back to the television set and/or the pc-screen. Recognizing well-known coasts and harbours or exploring new ones, watching popular activities and having the chance to interact at the same time attracted many viewers.

Our interviews indicate that not all of this was the result of conscious planning - the actors involved had not anticipated such extensive popular support. But the success inspired them to experiment with other slow television concepts - another boat and train journey, salmon fishing, knitting, etc. While these enjoyed a certain popularity none were as popular as Hurtigruten, partly because they did not have the same scope and composition, and partly because they were not the first. Successful innovation remains easier to explain than to predict.

\section{References}

Bessant J. \& Tidd, J. (2011) Innovation and Entrepreneurship. Second edition. Chichester: John Wiley \& Sons ltd.

Born, G. (2004) Uncertain vision: Birt, Dyke and the Reinvention of the BBC. London: Secker \& Warburg.

Christensen, C.M. (1997) The Innovator's Dilemma. N.Y.: Harper Business Essentials.

Dailey, L., Demo, L., \& Spillman, M. (2005) 'The Convergence Continuum: A Model for Studying Collaboration Between Media Newsrooms.' Atlantic Journal of Communication, 13 (3): 150-168.

Dayan, D. \& Katz, E. (1992) Media Events: the live broadcasting of history. Cambridge, Mass.: Harvard University Press.

Enli, G.S. (2007) The Participatory Turn in Broadcast Television. Institutional, editorial and textual challenges and strategies. PhD Thesis, Oslo: Acta humaniora.

Erdal, I.J. (2008) Cross-media news journalism. Institutional, professional and textual strategies and practices in multi-platform news production. PhD Thesis, Oslo: Acta humaniora.

Eriksen, T.H. (1996) Norwegians and Nature. available at: http://folk.uio.no/geirthe/Nature.html [Last accessed on April 29, 2014]

Habann, F.(2006) ‘Towards a Methodological Foundation of Media Innovation Research.' pp. 67-86 in: Zotto, C.D. \& van Kranenburg, H. (eds.) Management and innovation in the media industry. Cheltenham: Edward Elgar. 
Jenkins, H. (2006) Convergence Culture: where old and new media collide. New York: New York University Press.

Kjus, Y. (2005) 'Karnevalets formspråk i humor-TV'. Norsk medietidsskrift, 12 (3): 214-231.

Kjus, Y. (2007) 'Ideals and Complications in Audience Participation for PSM. Open Up or Hold Back?', pp. 135-150 in Lowe, J.F \& Bardoel, J. (eds.) From Public Service Broadcasting to Public Service Media. Nordicom: Göteborg.

Kjus, Y. (2009) Event media: television production crossing media boundaries. PhD Thesis, Oslo: Acta Humaniora.

Kulturrådet (2012) Norges dokumentarv. Available at: http://kulturradet.no/norges-dokumentarv

Lorenzen, M. (2009) 'Creativity in context. Content, cost, chance and collection in the organization of the film industry.' pp. 93-118 in Pratt, A.C. \& Jeffcutt, J. (eds.) Creativity, Innovation and the Cultural Economy. London and New York: Routledge.

Lowe, G.F. \& Bardoel, J. (eds.) (2007) From public service broadcasting to public service media. Göteborg: Nordicom.

Lowe, G.F. \& Hujanen, T. (eds.)(2003) Broadcasting \& convergence: new articulations of the public service remit. Göteborg: Nordicom.

Lowe, G.F. (ed.)(2009) The Public in public service media. Göteborg: Nordicom.

McQuail, D. (2005) McQuail's mass communication theory. London: Sage.

Nissen, C.S. (2006) Public service media in the information society. Strasbourg: Council of Europe.

NRK Plakaten. (2012) Available at: http://www.regjeringen.no/upload/KUD/Medier/NRK/NRK-plakaten_ per_18juni2012.pdf

Pfeffer, J. (1981) Power in Organizations. Cambridge, MA: Ballinger.

Philipsen, H. (2010) 'Creative cross-media communications and concepts', pp. 111-136 in Philipsen, H., Agerbæk, L., Walther, B.K., Arnfast, B.S,, \& Wildermuth, N. (eds.) Designing new media : learning, communication and innovation. København: Academica.

Puijk, R. (2011) 'Health and lifestyle to serve the public. A case study of a cross-media program series from the Norwegian Broadcasting Corporation.' Journalism Practice 6 (1): 75-91.

Puijk, R. (2013) 'Limits to change - organizational constraints on innovation.' Paper presented at Advancing Media Production Research conference. Leeds.

Schumpeter, J.(1947/1983) The theory of economic development: an inquiry into profits, capital, credit, interest, and the business cycle. New Brunswick, N.J.: Transaction Books.

Smith, E.G, Meurs L. van \& Neijens P.C. (2006) 'Effects of Advertising Likeability: A 10 year perspective', Journal of Advertising Research, 46 (1):73-83.

Sundet, V.S. (2008) 'Innovasjon og nyskaping i NRK - En analyse av plattform- og sjangerbruk i Rubenmann-prosjektet.' Norsk medietidsskrift 15 (4): 282-301.

Wurff, R. van \& Leenders, M. (2008) 'Media Organisational Culture and Innovative Performance.' pp. 151172 in: Zotto, C.D. \& van Kranenburg, H. (eds.) Management and innovation in the media industry. Cheltenham: Edward Elgar.

Ytreberg, E.(1999) Allmennkringkastingens autoritet: endringer i NRK Fjernsynets tekstproduksjon, 1987 1994. PhD Thesis, University of Oslo.

Roel PuiJk, Ph.D., Professor, Department Social Sciences, Film and Television Studies, Lillehammer University College, roel.puijk@hil.no 